\title{
Research on the ecological model of English Teaching
}

\author{
Jinghong Guo \\ Department of Basic Courses, \\ Suzhou Health College, Suzhou, China
}

\begin{abstract}
The traditional English teaching is an isolated process for teachers to carry out teaching activities, but with the development of the times, this kind of teaching method in the teaching practice has been unable to meet the requirements of the comprehensive development of students, nor really let students be able to learn the language of English in the process of economic globalization. With the continuous deepening of the reform of English teaching and the continuous development of ecological theory, the ecological teaching mode has gradually formed in the process of English teaching. English teaching process is regarded as a complete ecological system, and it is the basis of the activity of English teaching activities for positioning and in-depth analysis. Furthermore, it can a more scientific and effective guidance for the students' English learning activities. Introducing the mode of ecological theory in the process of English teaching activities, is not only conducive to the comprehensive and detailed investigation and analysis of English classroom teaching in the teaching environment, students and teachers. Furthermore, but also is it conductive to make a systematic study of the $t$ the new ideas and new ways' carrying of the English teaching activities. At this stage, ecological English Teaching of our country in terms of teaching facing the plight of all aspects of the language, the way and the environment, it is urgent to put forward effective measures to transform this present situation, and thus become a continual impetus of sustained and steady development of the ecological mode of English teaching.
\end{abstract}

KEY WORD- English teaching, ecological model, ecological theory

\section{Introduction}

Ecology, which was first proposed by German biologists in 1866, has developed into a comprehensive discipline with unique research methods and research values in the present century. At present, with the development of ecological value and ecological theory gradually has been widely used in various disciplines, educational ecology has emerged. In the field of modern education, it is generally believed that the compatibility of a comprehensive and relatively complete model of English teaching is helpful to balance the relationship between learning environment, students and teachers. However, the traditional English teaching methods can not be a good balance, too much attention to the teaching subject and subjectivity, teaching language, the education of the subjective initiative is not enough attention. Even some teaching activities will be regarded as the focus of teaching environment, the role of excessive emphasis on external factors. In the process of English teaching, it is advantageous to pay attention to the students and teachers, teaching environment, teaching methods and teaching language, which will help to improve the quality and efficiency of teaching activities.

\section{An overview of Eco-education}

\subsection{The meaning of Ecological Teaching}

The emphasis of ecological teaching lies in coordination, internalization, media and development. The concept of social culture has been introduced into the teaching mode, which is regarded as the basis of cognition and language expression. Under the guidance of the concept of social culture, the concept of ecological teaching gradually erected, that is, students, 
teachers, environment, language and other factors can reasonably be integrated into the scientific concept. Ecological teaching is the way and method of learning language, the time and space as the point of entry, and then summarizes the characteristics of the flow of language. In addition, ecological teaching also on the relationship between teaching environment and teaching subject were comprehensive explanation, and pointed out that, teachers provides the more relaxed and necessary environmental conditions for students learning activities of the language. The introduction of ecological model in the process of English teaching, is conducive to pay more attention to students and teachers, teaching environment, teaching methods and teaching language, which is conducive to improve the quality and efficiency of teaching activities.

\subsection{Characteristics of Ecological Teaching}

Ecological teaching extremely emphasize on the overall characteristics of English, it can come true an effective combination of language and its application practice and place, and it makes the sentence and the word have strong correlation and logic, which is helpful to the establishment of the similar pattern of the life body. A variety of language organizations interact with each other, and also effected by the current language environment, and gradually showing a similar system with the ecological system. Therefore, ecological teaching should face up to the special nature of language deconstruction, which can help them to play an effective role in English teaching.

\subsection{Ecological teaching system}

(1) The ecological role

In the process of English teaching, it is not only need to use systematic theory to analyze, but also need to study from the perspective of ecological theory. English teaching environment is similar to the non biological environment in the category of ecological theory, and the relationship between the student and the teacher is similar to the relationship between the consumer and the producer. As the knowledge and experience of decomposition, teachers bear of language, knowledge and detailed decomposition and integration of responsibility, in order to help students understand and grasp the knowledge and experience,teachers activities must be based on the learning environment, the application of language and the textbook.

(2) Ecological significance

The dynamic characteristics embodied in the ecological teaching methods are mainly embodied in the field of spatial and temporal changes in the process of English learning, which has a dynamic and overall influence on the students. The current English teaching mode is a teaching method which is based on the copying of the former mother tongue. In addition, English teaching is still in the process of mother tongue teaching has gained rich experience, and the establishment of a specific mode of thinking, also has a very far-reaching impact on the English teaching. Therefore, English teaching is a process of inheriting and accumulating experience, and it is also a dynamic process of development.

\section{Dilemma in English classroom teaching from the perspective of ecology}

\subsection{The quality of teaching subject is poor}

In the course of English teaching and learning in the ecological sense, students and teachers are the key factors which have a very important influence on the ecosystem. In the ecological model of English teaching, the relationship between students and teachers is not usually understood of the study and teaching, but the absorption of knowledge, internalization and the skills of teaching. At the same time, students can constantly expand the scope of knowledge of themselves, and not only limited to the scope of the teaching content of teachers. Current stage, students and teachers are in the process of teaching the subject, more serious problem between the two subjects is mainly manifested in the following aspects: the way which is used in teachers teaching activities is too unitary, the teaching idea obsolete; students lack enthusiasm to active learning, learning style is relatively rigid, schools' efficiency are comparatively low. In the field of ecology, the above 
problems will hinder the smooth operation of the ecological system.

\section{2. lack of rationality of teaching language}

In English teaching activities, the function of teaching language is similar to that of water in ecological system, which runs through every link in the process of ecological teaching. Students accept the language from teachers, it is equivalent to accept the teacher's own. The teaching process is the process of teaching language. Therefore, the teaching language has a very important significance for teachers. Related researches show that the teaching language used by teachers has a direct impact on the students' learning enthusiasm. The boring teaching language mainly displays in a large amount of knowledge and the frequency of the use of academic language is higher. In classroom teaching process, teachers do not have a detailed and profound analysis of the cultural background of the English language, but only use a very dull and boring language to explain, the role of communication and express meaning is difficult to play, which greatly reduces the students in the classroom learning efficiency.

\subsection{Single teaching method}

The English education in our country is more emphasis on the implementation of the concept of "people oriented". In the English classroom teaching, teachers pay more attention to the students' understanding of the teaching content. But in the part of English teaching, there are still some defects, which pay too much attention to the cultivation of students' three aspects of listening, reading and writing. At the same time, the majority of students learning English for the purpose of the examination, the target is too single. At the same time, the teacher's teaching ways are too single. Therefore, English teachers should pay more attention to every students, to mobilize students' factor effect.

\subsection{Overall imbalance of teaching environment}

English classroom teaching can be designed from three aspects of individuals, schools and society.
Individual level refers to the student's own economic conditions, interest in learning English, learning tools; school level is refers to the school library, teaching equipment, teachers, social level is the demand of English in their own social development, as well as from all sectors of society attitude towards learning English. The three level includes all the content in English teaching. But at present many surveys show that the teachers' educational level needs to be improved, teachers need to be optimized, the deconstruction of English textbooks in the content and the actual situation phenomenon. Therefore, the current imbalance of English teaching environment in our country is obvious, which seriously hinders the development of ecological teaching system in the teaching process.

\section{Ecological perspective to improve the effectiveness of English classroom teaching strategies}

\subsection{Improve the overall quality of teachers}

Students and teachers' English teaching system in the two most critical elements. Teachers play a main role in the teaching process, therefore, we should continue to expand their own knowledge, enrich the cultural connotation, learning and innovative teaching methods to improve the teaching effects. At the same time, teachers should help students to establish the correct learning objectives, mobilize the enthusiasm and initiative of the students, and constantly improve the level of teaching management, and build a good teaching environment. At the same time, as the beneficiaries of teaching activities, is the subject of learning activities, in the classroom to listen carefully, to actively think and answer questions, and more communities between teachers and students will come true. Therefore, in the teaching system, we should establish a good interaction model between teachers and students, so as to promote the sustainable and healthy development of micro ecosystem in English class. 


\subsection{Promote the rationality of teaching language}

In the ecological English teaching system, the teaching language is the most important "ecological factor", which has the function of connecting the various factors. In English teaching practices, proper application and comprehensively enhance the rationality of the teaching language, is not only helpful to enhance the teaching effect, but also to fully reflect the ecological factor in the ecological system in the teaching of an important role. In English teaching activities, we can improve the accuracy and the interest of the teaching language, and then strengthen the rationality of the teaching language.

\subsection{To promote the diversification of teaching methods}

Similar to the natural ecological system, the ecological system of English teaching also contains many elements, and there are also interrelated and contradictory relations among the elements. A variety of teaching methods can help to meet the requirements of English teaching from different angles, and it also helps to enhance the vivid and interesting of teaching activities. At the same time, they also contribute to the cultivation of students' creativity and learning enthusiasm. First of all, a variety of teaching methods are based on rich teaching content, according to the teaching syllabus to carry out teaching activities. Secondly, in the process of teaching, teachers should pay attention to the use of English in daily life, not only to enhance the students' writing ability, but also pay more attention to the cultivation of their communication skills. At last, teachers should take notice on the innovation of teaching content, and then support the development of ecological education system in the direction of diversification. This teaching model can promote the sustainable development of different "ecological factors", and promote the improvement of the whole ecosystem.

\subsection{Create a good teaching environment}

There is a relationship between macro teaching environment and micro ecosystem, which is not only promote each other but also restrict each other. Good macro environment can promote the better development of micro ecological system. Firstly, macro teaching environment is helpful for students to build correct teaching goals and get correct understanding of the purpose of the study, and then to develop good learning consciousness; secondly, micro ecological system helps to improve teachers' professional ability and comprehensive quality. In English teaching activities, teachers are the implementation of teaching activities, and their own ability level and teaching effect has a direct relationship between. At the same time, the choice of teaching materials, should not only pay attention to the characteristics of the times, but also suitable for students learning needs. In addition, the students should pay attention to the establishment of personal environment.

\section{Conclusion}

Industrial civilization provides the basis for the formation of ecological civilization, which is the product of human social civilization at a certain stage. In the environment of ecological civilization, English teaching activities need to be improved to meet the needs of the development of ecological teaching. English teaching plays a very important role in the teaching of higher education. At the same time, it has a great influence on the improvement and development of social culture. English teaching activities in the current stage to combined with the theory of ecological construction, and gradually establish a more comprehensive and systematic ecological teaching pattern. This teaching mode not only reflects the era characteristics, but also the improve teaching effect as the purpose, the progressive realization of the reform of teaching environment, teaching methods and the teaching language, and then contributing to the improvement of the overall environment, and fundamentally improve English classroom teaching effect. Therefore, ecological teaching mode provides an important basis for the healthy development of English teaching, and it is a new direction of the development 
of teaching mode in China.

\section{References}

[1] Zhou Wenjuan. New Horizons in Linguistics -Ecological linguistics $[\mathrm{J}]$. Yinshan academic journal, 2012. 72 .

[2] Fan Junjun. A review of the research on Ecological Linguistics $[\mathrm{J}]$. Foreign language teaching and research, 2000. 110.

[3] Liu Guiqin attaches great importance to the reform of College English teaching to improve the teaching quality of College English $[\mathrm{J}]$. Foreign language teaching and research, 2012.179. 